\title{
Neoclassical economics: science or neoliberal ideology?
}

\author{
David Slattery and Joseph Nellis* \\ Cranfield School of Management, Cranfield, Bedford, UK
}

Kosta Josifidis and Alpar Losonc

Department for European Economics and Business Novi Sad, Faculty of Economics Subotica, University of Novi Sad, Serbia

This paper calls for a new approach to economic theorising in the aftermath of the global financial crisis of 2007-2008. We examine two key theories which suggest that markets are stable self-correcting efficient systems. These theories, namely General Equilibrium Theory and the Efficient Markets Hypothesis, are at the heart of neoclassical economics and give neoliberal ideology much of its intellectual legitimacy. We demonstrate the flaws in these theories and the misleading prescriptions they provide for public policy. We suggest that these theories have survived, despite their inherent weaknesses, not as objective science but as ideology, and specifically allied to neoliberal ideology. We advocate a fundamental change of approach.

Keywords: neoclassical economics, general equilibrium theory, efficient markets hypothesis, neoliberalism

\section{JEL codes: $B 49$}

\section{INTRODUCTION}

The financial crisis of 2007-2008 provided a major shock to the global economy and represents a severe empirical test of neoclassical economic theory. In particular, the crisis, the subsequent long recession and continued volatility in financial markets raise questions about whether it is appropriate to describe markets in terms of 'equilibrium' or 'efficiency'. In turn, the crisis presents serious challenges to the advocates of neoliberalism, the political ideology which has dominated the debate on the management of the economy in much of the World for the last 30 years.

The focus of this paper is on neoclassical economic theory in the context of what the crisis tells us about the way that markets work in practice. We critically examine the conceptual foundations and premises of General Equilibrium Theory (GET) and the Efficient Markets Hypothesis (EMH) which are at the core of the neoclassical economic paradigm and which have had a major influence on public policy for many decades. We highlight conceptual flaws in GET and EMH and suggest that they do not stand up to empirical scrutiny. While these flaws in GET and EMH have been identified in the past, we argue that they have been glossed over in the development of the theories.

* j.g.nellis@cranfield.ac.uk.

Received 4 July 2012, accepted 5 February 2013 
In these circumstances, we ask why these theories have not only persisted but have been dominant for so long; and we question whether these theories, and the neoclassical paradigm, can be regarded as science or whether they have really just become part of an ideological approach to market systems.

We begin in Section 2 with a short summary of the underlying causes of the crisis of 2007-2008, noting that the analysis and the evidence emerged very quickly. We then turn to GET and EMH in Sections 3-5, identifying their fundamental weaknesses and considering the impact that these theories have had on public policy in the context of the financial crisis. In Section 6, we address the key question about the scientific status of GET and EMH. We describe neoliberalism and identify this ideology as one of the contributors to the persistence of the concepts of equilibrium and market efficiency. We conclude in Section 7 with a call for a radically new approach to economic theorising.

\section{THE FINANCIAL CRISIS OF 2007-2008: A SUMMARY}

Much has already been written about the causes of the crisis and there seems to be a wide consensus about what went wrong. A variety of contributions from governments and central banks, and from academics and journalists, all point to a number of features of the financial system and the global economy which led to the crisis. These features may be summarised as follows:

- Financialisation: the rapid growth of the financial sector relative to the real economy in a number of countries (in particular, the US and UK) in the decade leading up to the crisis, increasing financial innovation and the growth of 'shadow banking'.

- Securitisation: the development of new complex trading instruments where the risks within the underlying assets were disguised.

- Macro-economic factors: global trade and credit imbalances, a reduction in real risk-free interest rates, leading to cheaper credit and asset price inflation.

- The growth of consumer credit: the aggressive promotion of credit with the relaxation in credit criteria.

- The management of risk: the emergence of mathematical models purporting to quantify risk very precisely but providing false assurance to institutions and regulators that all was well.

- Network externalities: the complex web of transactions between financial institutions; to assess risk it was no longer sufficient to know your counterparty's risk, you needed to know your counterparty's counterparty's risk, etc.

- Leverage: as competition reduced the return on assets, financial institutions geared up to meet expectations for the return on equity; alongside this was the increased reliance by many banks on wholesale funding at the expense of retail deposits.

- Misaligned incentives: the short-term bonus culture and the moral hazard of institutions that were deemed to be too big to fail.

- Regulatory philosophy: based upon the assumption of efficient and rational markets, and a neoliberal agenda.

What is remarkable is that this analysis, and the empirical evidence supporting it, appeared so quickly after the onset of the crisis. For example, in December 2007, 
the European Union issued a comprehensive account of the changes in the structure of the financial markets and the failure of regulation (European Union 2007). In the UK, the Bank of England (Haldane 2009a; 2009b) and the Financial Services Authority (Turner 2009) had reached firm conclusions by the early part of 2009. In the US, Posner's (2009) A Failure of Capitalism was written in February 2009; see also Tett's (2009) Fool's Gold for a compelling account of how a group of bankers invented the new derivative instruments which spread through the financial system. We could mention many other contributions.

The evidence and the analysis of it did not, therefore, take long to assemble. The evidence was already available but was largely ignored because, we suggest, it conflicted with core concepts within neoclassical theory, the dominant paradigm in economics, and with the prevailing political ideology of neoliberalism, which shares those core concepts.

It is instructive to examine, for example, what the UK Financial Services Authority (FSA) refers to as 'the intellectual assumptions on which previous [pre-crisis] regulatory approaches have largely been built', both in the UK and elsewhere. At the core of these assumptions, according to the FSA, has been the theory of efficient and rational markets which involves five key propositions (Turner 2009, para. 1.4):

- Market prices are good indicators of rationally evaluated economic value.

- The development of securitised credit, since based on the creation of new and more liquid markets, has improved both allocative efficiency and financial stability.

- The risk characteristics of financial markets can be inferred from mathematical analysis, delivering robust quantitative measures of trading risk.

- Market discipline can be used as an effective tool in constraining harmful risk taking.

- Financial innovation can be assumed to be beneficial since market competition would winnow out any innovations which did not deliver value added.

It is clear from this FSA report that regulatory policy has been broadly based, over the last 30 years, upon a number of economic theories particularly from neoclassical economics. The core concepts of financial stability (implying equilibrium) and efficiency, delivered by market competition, come through strongly. We therefore now turn to examine these concepts.

\section{GENERAL EQUILIBRIUM THEORY}

Neoclassical price theory is the purest of the pure economic theory which has prestige status in economics (Arrow 1967). Equilibrium theory is the fundamental theory in economics (Hausman 1981). The equilibrium notion serves to make precise the limits of economic analysis: equilibrium thinking defines economic theorising (Hahn 1984). There is a widespread belief in economics that every economic theory must be fitted into the General Equilibrium mould if it is to qualify as rigorous science (Blaug 1980).

But, notwithstanding the status of GET within neoclassical economics, Arrow (1967) acknowledges that there is a degree of ambiguity and some scepticism within the profession about the descriptive power and normative utility of the theory. Arrow reviews the work of Samuelson and notes that Samuelson's papers show only the most oblique suggestions that the theory is descriptive of the real world. There is no flat 
denial in these papers, but Samuelson is guarded and agnostic. Arrow refers to the problem of the relationship between microeconomics and macroeconomics. Neoclassical microeconomic equilibrium with fully flexible prices presents an appealing picture of the mutual articulations of a complex structure, full employment being one of its major elements. What is the relation, Arrow asks, between this world and the real world with its recurrent tendencies to unemployment? Arrow does not think that the problem is solved by Samuelson's neoclassical synthesis. Arrow firmly believes that the mutual adjustment of prices and quantities represented by the neoclassical model is an important aspect of economic reality, but the Great Depression and the problems of developing countries suggest that something beyond, but including, neoclassical theory is required.

It was of course Keynes (1936) who first raised the challenge to classical theory which he regarded as a special case and not a general theory; and the characteristics of this special case happen not to be those of the economic society in which we live. The central question posed by Keynes was whether the economic system, in any significant sense, was self-adjusting (Clower and Leijonhafvud 1975). Keynesian economics rejects the market equilibrium framework for analysing the determination of quantities bought, sold and produced. Keynes's ideas have been developed by other theorists. Most relevant, for the focus of this paper, is Minsky's (1992) Financial Instability Hypothesis which he describes as a theory of the impact of debt on an economic system. Minsky observes that from time to time capitalist economies exhibit inflations and debt deflations that have the potential to spin out of control. Economies do not always conform to the classical precepts that they constantly seek equilibrium and are self-sustaining. Minsky proposes that an economy has financing regimes under which it is stable and financing regimes under which it is unstable. Also, over periods of prolonged prosperity, the economy transits from financial relations that make for a stable system to financial relations that make for an unstable system. Minsky suggests that business cycles of varying severity are endogenous within the financial system.

If there is a widespread acceptance that GET does not describe the real world, what is it about this theory that makes it so attractive? If we observe disequilibrium, the failure of markets to clear and periodic instability, why do economists persist with the notion of equilibrium? If GET has no empirical validity, why has it not been discarded?

Rosenberg (1992) addresses these questions from an epistemological and methodological perspective. He asks what it is that GET explains. It is not, he suggests, as if there is an empirically observed market phenomenon (equilibrium) that we seek to explain in terms of the behaviour of economic actors. Rosenberg considers whether economics is a branch of political philosophy, but settles for the conclusion that economics is applied mathematics. This conclusion chimes with the complaint made by Leontiff (1971) about the seemingly uncritical enthusiasm for mathematical formalism in economics and the lack of empirical foundations.

Mirowski (1989) approaches the questions from a historical perspective. Mirowski's basic thesis is that, starting in the 1870s, economists borrowed the concepts of physics, particularly the concept of energy which they associated with utility. The progenitors of neoclassical economic theory, he says, boldly copied the reigning physical theories of the 1870s. Mirowski argues that the concepts of energy in physics and utility in economics are metaphors; but while physics developed its metaphor so that the concept of energy today is now quite different from that which pertained in the 1870 s, economics has not developed in a similar way. He dubs the economic metaphor as 'proto-energetics', to reflect its basic foundations in mid nineteenth-century physics. 
Mirowski charts the development of economic theory, and the theory of equilibrium, from Walras, Jevons and Menger. He sees this development as a break from the classical past in that new metaphors were adopted. Mirowski says that an important step in this development was the adoption by Fisher, in his doctoral thesis of 1892, of the thermodynamic concepts of energy and equilibrium. One of Fisher's supervisors was J. Willard Gibbs, one of the founding fathers of thermodynamics. But there was, Mirowski continues, a fundamental problem in Fisher's thesis, which was identified by Gibbs (and which persists in economic theory to this day). It is generally known as the integrability problem. The issue is whether the energy metaphor, and the algebra that comes with it, can be appropriated into economic theory. In classical physics, the properties of energy are captured by their representation as an integral. But given its nature, the utility function is not so readily integrable. This problem was debated at length in the early years of the twentieth century, with critiques from a number of physicists. No solution to the problem was found and the ideas might have died; but, as Mirowski argues, neoclassical economics was given a new lease of life by Samuelson starting in the 1930s (Mirowski 1989).

In this context, it is interesting to note that Mirowski makes little mention of Keynes's challenge to economic theory, which arose at the same time. While Keynes challenged prevailing theory on largely empirical grounds, Mirowski focuses on the conceptual foundations and the parallel with physics. But it was, of course, Samuelson who led the attempt to reconcile Keynes's ideas with prevailing theory in the neoclassical synthesis. Thus, we suggest, Samuelson might be regarded as the saviour of equilibrium theory from attacks on both its conceptual and empirical foundations.

Mirowski is quite pointed in his criticism of Samuelson's role in disguising the fundamental conceptual weakness of equilibrium theory. 'Throughout his career, Samuelson has been the master of scientific rhetoric, continuously and consciously hinting at parallels between neoclassical theory and twentieth-century physics, and just as consciously denying them, usually in the very same article' (Mirowski 1989: 382). Mirowski sees Samuelson as responsible for the self-image of the neoclassical economist as a scientist. He says that the fundamental problem of incorporating the metaphors and associated algebra from physics into economics could not be overcome, but there was nothing else that could hold the (scientific) neoclassical research program together. Mirowski's answer to the question of why GET persists, despite its weaknesses, is that there is no alternative if economics is to maintain its image as the queen of the social sciences.

Smith/Foley (2008) provide a detailed comparison of classical thermodynamics and GET. They say that there are some very clear similarities between the two theories. Both theories seek to describe system phenomena in terms of constrained optimisation problems. Both rely on dual representations of interacting subsystems: the state of each subsystem is represented by pairs of variables, one characterising its content and the other the way it interacts with other subsystems. Thus in economics, according to the authors, the content is represented by the amount of commodities held by an agent and the interaction is represented by the price at which one commodity can be traded for another. Three basic laws defining classical (reversible) thermodynamic systems have exact counterparts in what the authors refer to as quasi-linear economies (or essentially reversible systems). Utility does not, however, correspond to energy but is more like entropy.

But Smith/Foley demonstrate how the comparison between thermodynamics and economics breaks down when we consider irreversible (path-dependent) systems. Thermodynamics clearly distinguishes between reversible and irreversible phenomena. 
The theory generates deterministic predictions by measuring system structure through reversible transformations. Outcomes of irreversible transformations can be predicted only if they suffer no path-dependence and therefore coincide with the outcomes of other transformations which could be performed reversibly.

The weakness of GET is that it does not distinguish between reversible and irreversible transformations. The basic proposition of GET is that economic agents each hold an endowment bundle of commodities with different offer prices. Trading in the market then results in equilibrium where offer prices coincide. But this is an inherently irreversible process since it is impossible to induce economic agents, acting rationally, to voluntarily accept transactions that reduce their utility. The goal of GET is to derive a particular Pareto allocation directly from the endowments and preferences of individual agents but this goal is unattainable, in the same way that it is impossible to predict the path of irreversible transformations in thermodynamics.

Smith/Foley argue that GET conflates two very different thought experiments. In the first, they envisage a system in equilibrium where one agent is disturbed away from his equilibrium configuration. The system can easily absorb this disturbance and the outcome is determinate. In the second experiment, a shock changes the offer prices of all economic agents in different ways. The whole economy is moved far from equilibrium. Exchanges among agents can bring the system back into equilibrium but this process is not determinate. Further, well-defined market prices do not exist when systems are far from equilibrium; the assumption that such prices exist (albeit non-equilibrium prices) is a fundamental weakness in much economic theorising.

We argue therefore that GET, even as a pure abstract theory, contains a fundamental conceptual flaw. We reach this conclusion if we approach either the issue of the non-integrability of the utility function or the problem of the irreversible path-dependent process towards equilibrium. But further, there is a question about the extent to which the concept of equilibrium can ever be appropriate to economic phenomena.

We return to consider the implications of this conclusion after considering the second fundamental idea on which neoliberal ideology relies, namely the Efficient Markets Hypothesis (EMH).

\section{THE EFFICIENT MARKETS HYPOTHESIS}

This proposition has its origins in the observation that the prices of securities and commodities in markets appear to follow a random walk. The notion of efficiency became attached to this phenomenon largely following the work of Fama (1970: 383): 'a market in which prices always "fully reflect" available information is called "efficient" (his quotation marks).

Now the immediate question which arises from Fama's statement is 'why?'. Why is a market in which prices always fully reflect available information called 'efficient' (as opposed to some other term)?

Within neoclassical economics, the word 'efficiency' has two meanings (Samuelson/ Nordhaus 1995). First, the authors say, it is associated with Pareto optimality. Efficiency, as economists define it, is a state in which the maximum amount of consumer satisfaction is squeezed out of society's resources. An 'efficient' situation is one where no one can be made better off without making someone else worse off. Second, 'efficiency' has a different meaning in finance theory associated with the Efficient Markets Hypothesis (EMH). Here 'efficiency' means that information is 
quickly absorbed, not that resources produce the maximal outputs (Samuelson/ Nordhaus 1995: 264, 499).

In its first meaning outlined above, 'efficiency' is a corollary of General Equilibrium Theory (GET) and provides the foundation of Welfare economics. In its second meaning, 'efficiency' provides the foundations of Finance theory. Thus, in a standard text on Principles of Corporate Finance (Brealey and Myers 2000: 351), students are exhorted to learn 'the six lessons of market efficiency' including 'trust market prices'. In an efficient market you can trust prices, for they impound all available information about the value of each security.

So in EMH the word 'efficiency' has a different meaning than elsewhere in economics; and we could add that it has a different meaning than in science and technology. In technology, for example, the efficiency of a machine is a performance measure: the measure (as a percentage) of the output of a machine compared with its input or with some standard, which could be an idealised engine. Likewise in economics we could refer to the efficiency of a factory or of the productive economy as a measure of the extent to which maximum productive capacity is being used at any point. Alternatively, the notion of efficiency can be identified with Pareto optimality in a perfectly competitive market: if we envisage a market with imperfections then at least in conceptual terms we can attach an efficiency percentage to that market in comparison with the perfect ideal - that is, as a measure of the degree to which Pareto optimality is achieved. More specifically, in the context of stock markets, an efficiency measure could assess the extent to which, in the long run, stock prices reflect the underlying earnings of companies, and thereby provide good signals for the allocation of investment funds. Over-pricing or under-pricing could be evidence of a degree of inefficiency. However, EMH is not stated in terms of the relationship between stock prices and corporate earnings, but in terms of the incorporation of information into prices.

In EMH, the word 'efficiency' is not formally defined as a performance measure but as an attribute of the market. A market which satisfies the criterion is defined as efficient. But further, the implication of EMH is that markets generally have this property, and therefore all markets are efficient. To quote Shiller (2005: 177): 'The efficient markets theory asserts that all financial prices accurately reflect all public information at all times. In other words, financial assets are always priced correctly, given what is publicly known, at all times. Prices may appear to be too high or too low at times but, according to the efficient markets theory, this appearance must be an illusion' (author's emphasis).

Clearly, we argue, EMH leaves no room for markets to be regarded as inefficient to any degree or as having in any sense a sub-optimal performance. While the use of the term 'efficiency' in EMH is different from that used elsewhere in economics and in science and technology, the implication is that the term can be understood in the same way - that is, as an indication of performance. While EMH is defined in terms of the reaction of prices to information (which limits the empirical ground on which the theory can be tested), the implication of EMH is that markets behave in a desirable way which constitutes 100 per cent efficiency.

The purpose of this article is not to add to the already voluminous literature on EMH. In contrast to GET, EMH has been one of the most controversial theories within economics and finance over the last 40 years. Instead, our objective is to use EMH as an example of a theory which has been influential within neoclassical economics and finance, and which has had a substantial impact on public policy (for example, in regulatory policy as identified above). It is in this context that we ask why it is that the 
term 'efficiency' has been associated with the apparent random nature of stock market prices.

It is instructive to refer back to Fama's first major article on the subject in 1965. This is how Fama summarises the argument presented in the paper (Fama 1965: 90):

We saw in Section II that a situation where successive price changes are independent is consistent with the existence of an 'efficient' market for securities, that is, a market where, given the available information, actual prices at every point in time represent very good estimates of intrinsic values. (Author's italics and quotation marks)

This is a very different proposition from the one presented in 1970. It hypothesises that market prices correlate well with intrinsic values. This is a proposition that can be tested and has since been tested. Shiller $(2005: 3,191)$ shows, in studies of the US stock market from 1871 to 2005 , that stock prices do not correlate well with corporate earnings and that volatility in prices cannot be accounted for in terms of volatility in dividends.

So the question arises of why Fama changed the proposition between 1965 and 1970. In his 1970 article, he makes no reference to the previous formulation of the theory. He does, however, acknowledge that the new formulation is so general that it has no empirically testable implications. He says that, to make the model testable, the process of price formation must be specified in more detail. In essence, he says, we must define somewhat more exactly what is meant by the term 'fully reflect'. He then refers to the assumption made in previous work that conditions of market equilibrium can (somehow) be stated in terms of expected returns. Fama then sets out the mathematical formulism which he suggests makes the theory testable. However, LeRoy (1976) criticises the definitions in this formalism as being true as tautologies and argues that, contrary to Fama's implication, the equations cannot properly generate testable implications. Fama (1976) disagrees. But the point is well made. The problem with EMH is that it effectively defines markets as being efficient and in such a way as to make it difficult or impossible to disprove. It is argued, however, by advocates of the theory, that the empirical evidence supports the theory; and the proposition that market prices are good measures of underlying value still remains by implication but protected from empirical testing.

The 1965 formulation of the theory was a reasonable hypothesis, in scientific terms, as it can clearly be tested. By comparison, the 1970 version is not a reasonable hypothesis and for this reason, we argue, it is not scientific. The fact that the 1965 hypothesis cannot be upheld (as demonstrated, for example, by Shiller 2005) might have been anticipated at the time from the experience of the 1929 crash and the work of Keynes. We may wonder, therefore, if the formulation of the theory was changed to one which was more immune to empirical test, or at least only testable on the ground defined by the hypothesis.

In his 1970 article, Fama recounts the history of the study of stock market phenomena and refers to a large body of empirical results in search of a rigorous theory (Fama 1970: 389). We suggest that, more than 40 years after that statement, there is even more empirical evidence in search of a rigorous theory. EMH is not that theory, since it does not present a framework which can adequately incorporate the results of empirical studies. We have of course learnt a great deal about the market, about the behaviour (rational or otherwise) of investors, about how prices diverge from the underlying earnings of companies, about booms and busts. But we have no fundamental theoretical market model that commands wide acceptance within the profession. EMH should be credited with catalysing a good deal of the research effort, but 
in other respects it has been a source of unnecessary controversy and a distraction from what might otherwise have been an effort to find a unifying theory.

\section{NEOCLASSICAL ECONOMIC THEORY AND THE FINANCIAL CRISIS}

So far, we have examined the conceptual foundations of two key theories which are related to neoclassical economics, and argued that both theories have fundamental weaknesses. So how do they perform in the empirical test provided by the financial crisis of 2007-2008?

A good theory should provide understanding and insight, and, as appropriate to the circumstances, a degree of predictive power. Economic systems are complex, and as such the predictive power and forecasting ability of any theory will be limited. But a good theory should at least identify risks and assign some probabilities of those risks arising. A good theory will also provide reliable prescriptions for public policy.

Against this test, however, and in the context of the financial crisis, neoclassical theory cannot be regarded as successful. The theories underlying neoclassical economics, and particularly GET and EMH, are predicated against the existence of crises. The key messages of these theories are that markets are stable, self-correcting and efficient systems. Crises should not happen, and hence there is no prescription for when they do arise. We may note that in his textbook, Economics (1973: 266), Samuelson writes: 'Although nothing is impossible in an inexact science like economics, the probability of a Great Depression - a prolonged, cumulative and chronic slump like that of the 1930 s, the 1890 s or the 1870 s - has been reduced to a negligible figure. No one should pay any appreciable insurance premium to be protected against the risk of a total breakdown in our banking system ...'. Moving forward to the 2007-2008 crisis and to what some are now calling the 'Great Recession', Lucas said in September 2007 that he was sceptical that the sub-prime crisis would spread to the whole mortgage market, and in September 2008 he was sceptical that the economy would slip into recession (quoted by Posner 2009: 254).

A key feature of the crisis of 2007-2008 was the failure of the risk models adopted by financial institutions, rating agencies and regulators. These models have been built upon neoclassical finance theory and have been incorporated into regulatory systems. Not only did these models fail to provide an early warning of the crisis, they signalled the all-clear (European Union 2007). According to Haldane (2009a), the models were fundamentally wrong.

Neoclassical theories also provided support for developments in practice which proved to be harmful in promoting or exacerbating the crisis. Of particular significance is the practice, and frequently the regulatory requirement, for financial institutions to 'mark to market' their balance sheets. This arises from the implication of EMH that the market price represents the best estimate of intrinsic economic value.

In a rising market, mark to market increases apparent profits and therefore executive and trader bonuses. This, in turn, reinforces confidence and increases the risk of irrational exuberance. In a falling market, mark to market has the opposite effect of crystallising losses. When the downturn in 2007 was triggered by defaults on US sub-prime mortgages, losses in financial institutions started to mount. This substantially reduced confidence, particularly in the creditworthiness of financial institutions. No one knew which institutions were carrying large losses and, as a result, inter-bank lending fell dramatically. This, in turn, led to severe problems for banks relying on wholesale funding (for example, Northern Rock in the UK which had a run on its deposits). 
As we pointed out above, the proposition that market price represents the best estimate of intrinsic value is not in fact one that is tested within EMH. This proposition is protected from testing by EMH by insisting that empirical study is limited to the question of whether information is incorporated into prices. EMH does not involve a comparison of different methods of valuation.

Further, financial institutions normally hold long-term positions in mortgages, corporate bonds, government securities and equities. Measuring the value of these assets by a continuously moving daily price is not appropriate. This method values each institution on a liquidation basis rather than a going-concern basis. This method is particularly inappropriate for those financial institutions such as insurance companies and pension funds which also hold long-term liabilities. Mark to market effectively conflates illiquidity and insolvency.

The pre-eminence of notions of equilibrium, stability and self-correcting mechanisms in markets therefore provides potentially misleading prescriptions for public policy. As periods of growth and recession, and occasional crises, are rationalised within this framework, lessons that could otherwise be learnt about the inherent instability of the financial system are in danger of being overlooked. Alternative theories, such as Minsky's (1992), are dismissed or ignored. Thus, the crisis of 2007-2008 came as a surprise to most observers. Over-confidence in the boom is replaced by under-confidence in the bust. Both are equally damaging.

Consider what the prescription might be if we acknowledge that upswings and downswings are a normal part of the economic cycle and that these will be punctuated by occasional crises on a longer timescale. If economists, central bankers and politicians were to acknowledge that we cannot prevent these gyrations, only dampen them, how would that affect business and consumer behaviour? Such messages would need to be carefully crafted, and could be disturbed by sections of the media that misrepresented the messages. But if businesses and consumers were prepared for upswings and downswings, we might succeed in moderating behaviour so as to prevent irrational exuberance on the way up and lack of confidence on the way down.

\section{NEOCLASSICAL ECONOMICS: SCIENCE OR NEOLIBERAL IDEOLOGY?}

In the above discussion, we have highlighted fundamental conceptual flaws in, and a lack of empirical support for, two key concepts within neoclassical economics.

In the case of GET, these issues have long been recognised. As mentioned earlier, the integrability problem was identified early in the twentieth century. Also, it has been recognised, at least since the time of Keynes, that GET does not represent the real world. The judgement of EMH is harsher in that it appears that the theory has been constructed to promote the proposition that markets are efficient per se, and not as a scientific theory aimed at assessing the efficiency of markets.

So the question arises of why GET and EMH, and the core concepts of market equilibrium and efficiency, have not only persisted but also been dominant in shaping public policy. Evaluated on scientific criteria, both theories should either be substantially revised or discarded.

A comparison with the natural sciences is again instructive. The natural sciences benefit from a small number of very fundamental and empirically validated theories which hold together the various disciplines and provide a secure framework for research. Economics only has GET as a contender for the unifying theme, and GET 
is flawed. But as Mirowski (1989) suggests, there is nothing else to hold economics together and to maintain the image of economics as rigorous science.

But there is another reason why these theories and concepts persist, and that relates to the emergence and dominance in public policy discussion of neoliberal ideology.

Neoliberalism, as it is understood today, has its origins in the formation of the Mont Pelerin Society in 1947 under the leadership of Friedrich Hayek, who had just written The Road to Serfdom (Hayek 1944; Mirowski and Plehwe 2009; Turner 2008; Van Horn 2009). The expressed purpose of the Society was to combat what the members saw as 'state ascendancy and Marxist or Keynesian planning sweeping the globe' (Mont Pelerin Society 2005). Members of the Society originally referred to themselves as neoliberals (Mirowski and Plehwe 2009). Some authors (see, for example, Hay 2004 and Harvey 2005) attribute the origin of neoliberalism to Reagan and Volker in the US and to Thatcher in the UK in the 1980s. But it is more correct to say that the early 1980s was the point at which neoliberalism first made a significant impact on public policy. ${ }^{1}$

Neoliberalism is not a succinct and clearly defined philosophy. It should not simply be conflated with neoclassical economics since neoliberals include economists of the Austrian School and also advocates of rational expectations theory, both of which to some degree depart from the theories of neoclassical economics. Also, in the US, the movement is not usually referred to as neoliberalism, but is more associated with neoconservatism (Mirowski and Plehwe 2009). However, the authors cited above all agree that neoliberalism includes a set of fundamental principles which can be summarised as follows:

- A general belief in the efficacy and efficiency of the free market mechanism in allocating scarce resources; a belief in global free trade and free capital mobility; a belief that unfettered free markets produce a natural spontaneous order which is self-regulating and self-correcting.

- An advocacy of a limited and non-interventionist role for government in managing markets; the rejection of Keynesian demand-management techniques in favour of monetarism, neo-monetarism and supply-side economics; an advocacy of deregulation and privatisation.

- A commitment to the rule of law, to individual freedom and personal responsibility and to private property rights.

Implicit in these principles, in the reference to free markets producing a natural spontaneous order which is self-regulating and self-correcting, is the concept of market equilibrium. Explicit is the concept of market efficiency. There is a strong correlation, therefore, between these neoliberal beliefs and the core concepts in GET and EMH. In terms of history, equilibrium theory has its origins in the late nineteenth century. Interest in a rigorous proof of a general equilibrium waned somewhat during the more pragmatic, empirically oriented Marshallian period, ${ }^{2}$ but GET revived, particularly after it was 'proved' in its most rigorous form in 1954. EMH developed in the postwar period, with its most general proposition dating from 1970. Neoliberalism grew from 1947.

1. It may be argued that the Mont Pelerin Society's most influential moment came somewhat earlier when scholars like Machlup and Friedman advised Nixon on flexible exchange rates to replace the gold exchange standard following the collapse of the Bretton Woods Agreement. We are grateful to a referee for pointing this out.

2. This tradition does, of course, still continue in practice today, as a necessary tool for everyday microeconomic analysis. 
The core ideas of market equilibrium and efficiency have since developed and grown in importance in public policy decisions, both as part of neoclassical economic theory and as part of neoliberal ideology.

Neoliberalism has been adopted across the globe not just in developed economies, but also in former Soviet bloc states and in other developing countries. The advocates of the neoliberal way now occupy positions of considerable influence in education, the media, corporate boardrooms and financial institutions as well as key state institutions and international institutions such as the IMF and the World Bank (Harvey 2005). We suggest, however, that neoliberalism may be found in its purest forms in the US and the UK.

We mentioned earlier the report issued by the UK Financial Services Authority (Turner 2009) identifying the assumptions on which regulatory policy has been built in the UK and elsewhere. We can recognise in these assumptions the influence not only of neoclassical concepts of market equilibrium and efficiency, but the wider neoliberal principles outlined above.

Konings (2009) makes the point, however, that we must not confuse the rhetoric of neoliberals with the reality of neoliberalism. Konings argues that neoliberalism has not in practice led to a withdrawal of the state from regulating markets. On the contrary, the neoliberal era has seen the growth of institutional control accompanied by the increased power of elites which have privileged access to the state's organising mechanisms. 'Re-regulation' is not, therefore, the solution to the financial crisis. Slattery and Nellis (2011) make similar points, arguing that the state cannot be seen as being somehow outside the economic system. The state provides the framework of law which creates the foundations of the economic system; and public finance and private finance are intimately linked. The idea of a 'free market', a market free of state intervention, fails to recognise this reality. Market participants, politicians and government officials are all actors on the same stage. Neoliberalism, therefore, has resulted not in the withdrawal of the state as such, but in a much more subtle change in the role of the state and of the relationship between the principal (and powerful) actors on the political-economic stage.

Neoliberalism is, therefore, a complex phenomenon. For the purposes of this article, however, it is sufficient to recognise the correlation between the neoliberal belief in the stability and efficiency of the market system and key theories in neoclassical economics, namely GET and EMH. Neoliberalism and neoclassical economics have a strong symbiosis and together they have had a substantial influence on public policy in the common promotion of the core concepts of market equilibrium and efficiency.

In this context it is difficult if not impossible for neoclassical economics to be an independent science. At least until the financial crisis of 2007-2008, it was not easy for economists to dispute the validity of the concepts of equilibrium and efficiency of markets. As we mentioned above, heterodox voices struggled to be heard. But even now there is a risk that after a period of time, when economies emerge from recession and governments overcome their structural fiscal deficits, the old order will re-establish itself and the opportunity for reform will be lost. We can see how this happened after the last major comparable crisis in the 1930s.

It is instructive to go back to the opening remarks in Keynes (1936). He begins by saying that his book is chiefly addressed to his fellow economists; his objective is to persuade economists to re-examine critically certain of their basic assumptions. Did he succeed? Samuelson (1973: 205) says that in recent years 90 per cent of American economists have stopped being 'Keynesian economists' or 'anti-Keynesian economists'. Modern economists, he continues, are 'post Keynesian, keen to render obsolete 
any theories that cannot meet the test of experience'. Lucas says that Keynes's influence was almost entirely political. He thinks that the intellectual forefathers of modern economics are Smith, Ricardo and Marshall, and our teachers are Arrow, Friedman and Samuelson (Lucas, quoted by Parkin 2000: 178). Thus, Keynes had no influence on the development of mainstream economic theory according to two of its leading proponents, Samuelson and Lucas; they write him out of the script. Keynes's theories have of course been disputed, but what has been ignored is his challenge to the basis of economic theory - that is, that it represents a special case, and one which is not realistic.

The concept of equilibrium has, therefore, survived and prospered. The word 'efficiency' took on a new meaning in EMH. With the promotion of the concepts of market stability and efficiency within neoliberal ideology, and with the increasing influence of that ideology on public policy, these concepts became effectively immune to scientific challenge. We therefore ask whether neoclassical economics can be regarded as a rigorous science or whether it has just become allied to, or part of, neoliberal ideology.

\section{CONCLUSION}

In this paper, we have critically examined two key theories at the heart of neoclassical economics. We have identified their fundamental conceptual weaknesses and their failure in practice in the domain of public policy. We have questioned why these theories have survived, despite their conceptual weaknesses and lack of empirical validation. Our answer is that both theories have been allied to and promoted by neoliberal ideology and, in the case of GET, by the fact that there is nothing else to hold the neoclassical economic paradigm together.

So, we argue, the time has come to publicly acknowledge the weaknesses of current market theories and, indeed, to recognise that they do not satisfy scientific criteria. This, in turn, provides a strong signal to neoliberal ideology that its prescriptions for public policy are not based upon sound intellectual foundations. The crisis of 2007-2008 provides a unique opportunity to re-evaluate our core theories and beliefs, and to initiate a new research agenda free of the constraints of unsatisfactory concepts such as equilibrium and market efficiency.

We are, of course, not the first to call for a change in the paradigm of economics. Many authors, both before and after the crisis, have pointed to the fundamental problems of neoclassical economics and the failure of theory to represent the real world. We add our modest contribution to this line of heterodox literature. The challenge of replacing the existing paradigm is great, and can only be achieved by a persistent collective endeavour among those who do not share the assumptions and conclusions of neoclassical theory.

\section{REFERENCES}

Arrow, Kenneth J. (1967): Samuelson collected, in: Journal of Political Economy, 75(5), 730-737. Blaug, Mark (1980): The Methodology of Economics, Cambridge, UK: Cambridge University Press. Brealey, Richard A., Myers, Stewart C. (2000): Principles of Corporate Finance, 6th edn, Boston: Irwin McGraw Hill.

Clower, Robert, Leijonhafvud, Axel (1975): The coordination of economic activities:

a Keynesian perspective, in: American Economic Review, 65(2), 182-188. 
European Union (2007): Financial supervision and crisis management in the EU, European Parliament Committee on Economic and Monetary Affairs, IP/A/ECON/IC/2007-069.

Fama, Eugene F. (1965): The behaviour of stock market prices, in: Journal of Business, 38, 34-105.

Fama, Eugene F. (1970): Efficient capital markets: a review of theory and empirical work, in: The Journal of Finance, XXV(2), 383-417.

Fama, Eugene F. (1976): 'Reply' (to Leroy, 1976), in: The Journal of Finance, XXXI(1), 143-145.

Hahn, Frank (1984): Equilibrium and Macroeconomics, Oxford: Basil Blackwell.

Haldane, Andrew G. (2009a): Why banks failed the stress test, Bank of England, URL: http:// www.bankofengland.co.uk/publications/speeches/2009/speech374.pdf.

Haldane, Andrew G. (2009b): Small lessons from a big crisis, Bank of England, URL: http:// www.bankofengland.co.uk/publications/speeches/2009/speech397.pdf.

Harvey, David (2005): A Brief History of Neoliberalism, New York: Oxford University Press.

Hausman, Daniel (1981): Capital, Prices and Profits, New York: Columbia University Press.

Hay, Colin (2004): The normalising role of rationalist assumptions in the institutional embedding of neoliberalism, in: Economy and Society, 33(4), 500-527.

Hayek, Friedrich A. (1944): The Road to Serfdom, London: Routledge.

Keynes, John Maynard (1936): The General Theory of Employment, Interest and Money, New York: Harcourt, Brace and Co.

Konings, Martijn (2009): Rethinking neoliberalism and the subprime crisis: beyond the re-regulation agenda, in: Competition and Change, 13(2), 108-127.

Leontiff, Wassily (1971): Theoretical assumptions and non-observed facts, in: American Economic Review, 61, 1-7.

LeRoy, Stephen F. (1976): Efficient capital markets: comment, in: The Journal of Finance, XXXI(1), 139-141.

Minsky, Hyman P. (1992): The financial instability hypothesis, Levy Institute Working Paper No 74, URL: http://www.levyinstitute.org/pubs/wp74.pdf.

Mirowski, Philip (1989): More Heat than Light: Economics as Social Physics, Physics as Nature's Economics, Cambridge, UK: Cambridge University Press.

Mirowski, Philip, Plehwe, Dieter (2009): The Road from Mont Pelerin: The Making of the Neoliberal Thought Collective, Cambridge, MA: Harvard University Press.

Mont Pelerin Society (2005): Inventory of the General Meeting Files (1947-1998), Liberaal Archief, Ghent, Belgium, URL: http://www.liberaalarchief.be/MPS2005.pdf.

Parkin, Michael (2000): Macroeconomics, 5th edn, Reading, MA: Addison-Wesley.

Posner, Richard A. (2009): A Failure of Capitalism: The Crisis of '08 and the Descent into Depression, Cambridge, MA and London, UK: Harvard University Press.

Rosenberg, Alexander (1992): Economics: Mathematical Politics or Science of Diminishing Returns? Chicago and London: University of Chicago Press.

Samuelson, Paul A. (1973): Economics, 9th edn, New York: McGraw Hill.

Samuelson, Paul A., Nordhaus, William D. (1995): Economics, 15th edn, New York: McGraw Hill.

Shiller, Robert J. (2005): Irrational Exuberance, Princeton, NJ and Oxford, UK: Princeton University Press.

Slattery, David, Nellis, Joseph G. (2011): Rethinking the role of regulation in the aftermath of the Global Financial Crisis: the case of the UK, in: Panoeconomicus, LVIII(3), 407-423.

Smith, Eric, Foley, Duncan K. (2008): Classical thermodynamics and economic general equilibrium theory, in: Journal of Economics and Control, 32(1), 7-65.

Tett, Gillian (2009): Fool's Gold: How Unrestrained Greed Corrupted A Dream, Shattered Global Markets and Unleashed a Catastrophe, London: Little, Brown.

Turner, Adair (2009): The Turner Review: A Regulatory Response to the Global Financial Crisis, London: Financial Services Authority.

Turner, Rachel S. (2008): Neo-Liberal Ideology: History, Concepts and Policies, Edinburgh: Edinburgh University Press.

Van Horn, Rob (2009): Reinventing monopoly and the role of corporations: the roots of Chicago law and economics, in: Mirowski, Philip, Plehwe, Dieter (eds), The Road from Mont Pelerin: The Making of the Neoliberal Thought Collective, Cambridge, MA: Harvard University Press, 204-237. 